\title{
Naar nieuwe scheidslijnen op de Nederlandse arbeidsmarkt? Een pleidooi voor uitvoerbaarheid van beleid
}

\author{
Maroesjka Versantvoort \& Kim Putters*
}

\section{Inleiding}

Mensen die zich op de arbeidsmarkt begeven, zijn anno 2020 niet alleen bezig met het vinden en houden van werk. Steeds meer komen verschillende leefdomeinen voor hen samen. Zo zien we dat het aandeel werkenden op de Nederlandse arbeidsmarkt die ook mantelzorg verlenen stijgt, evenals het aantal uren dat men zorg verleent. Inmiddels is 17 procent van alle werkenden mantelzorger (Josten e.a., 2019). Vergeleken met andere EU-landen ligt de scholingsdeelname in Nederland hoog (Maslowski, 2019). Van de werkenden uit 2016 had 40 procent in de voorafgaande twee jaar (werkgerelateerde) scholing gevolgd (Portegijs, 2019). Een leven lang leren wordt steeds meer als voorwaarde beschouwd voor duurzame inzetbaarheid. Ten aanzien van scholing zijn er tegelijkertijd allerlei onzekerheden. Zo stelt 15 procent van de jongeren in Nederland niet de juiste opleiding te hebben. En een leven lang ontwikkelen lijkt voor hen minder van de grond te komen door de toename in flexibele banen - waar relatief weinig investeringen in scholing plaatsvinden en waar jongeren vooral in werkzaam zijn (SER, 2019). Jongvolwassenen die werk en zorg combineren voelen zich vaak belast en ondervinden problemen om alle verantwoordelijkheden te combineren (SER, 2019). Dit kan zorgen voor gevoelens van onzekerheid. In dit kader hebben recent de commissie-Borstlap en de Wetenschappelijke Raad voor het Regeringsbeleid (WRR) aanbevelingen gedaan om die onzekerheid te verminderen en de duurzaamheid van arbeidsdeelname van verschillende groepen op de arbeidsmarkt te vergroten (Commissie Regulering van Werk (2020) en WRR (2020).

Bovenstaande ontwikkelingen roepen vragen op over het ontstaan van nieuwe sociale scheidslijnen op de arbeidsmarkt, bijvoorbeeld tussen flexwerkers en mensen met een vast contract, tussen hoog- en lageropgeleiden of tussen mensen met een meervoudige taakbelasting en anderen. We gaan daartoe eerst in op een aantal belangrijkste trends op de arbeidsmarkt. Daarna bespreken we een aantal cases ter verdieping, en ten slotte geven we duiding aan de relevantie van scheidslijnen op de arbeidsmarkt in de komende tijd.

* Dr. ir. Maroesjka Versantvoort is verbonden aan het Sociaal en Cultureel Planbureau als programmaleider 'Dynamiek op de arbeidsmarkt'. Prof. dr. Kim Putters is directeur van het Sociaal en Cultureel Planbureau. 


\section{Trends in arbeidsmarktbeleid: flexibeler, langer en inclusiever werken en leren}

Een dynamisch arbeidsmarkt. Dat is wat werkzoekenden, werknemers en werkgevers voelen (CBS/TNO, 2019). Ontwikkelingen als internationalisering, vergrijzing, flexibilisering en aanpassingen aan de verzorgingsstaat hebben hun weerslag op de mogelijkheden en risico's van mensen op die arbeidsmarkt. De werkloosheid is in de achterliggende jaren sterk gedaald, maar dat levert niet voor iedereen werkzekerheid op. Zekerheden zijn verdwenen voor sommigen. Anderen ervaren weer nieuwe kansen. Zijn zich nieuwe scheidslijnen aan het ontwikkelen? De overheid streeft naar een inclusieve arbeidsmarkt waarbij iedereen naar vermogen meedoet: vrouwen en mannen, jongeren en ouderen, laag- en hoogopgeleiden, minderheden en autochtonen, mensen met en zonder arbeidsbeperking, mensen met een vast en mensen met een flexibel contract of zelfstandigen. Uitgangspunt is dat iedereen gelijke kansen op werk, doorstroom en een prettige werkomgeving zou moeten hebben.

Een aantal ontwikkelingen lijkt het streven naar een inclusieve arbeidsmarkt, dus een arbeidsmarkt waar iedereen in de gelegenheid is om vaardigheden doorlopend te blijven ontwikkelen via bijvoorbeeld om- en bijscholing, waar arbeidsmarktdiscriminatie wordt tegengegaan en waar onder meer mensen met beperkingen worden ondersteund om zo volwaardig mogelijk mee te doen, onder druk te zetten.

Een van die ontwikkelingen is de verdergaande flexibilisering. Een steeds groter deel van de beroepsbevolking werkt in een flexibele arbeidsrelatie. Inmiddels werkt in Nederland ongeveer één op de drie personen op basis van een flexibele arbeidsverbintenis - tegen één op de vier in 1996, variërend van mensen met tijdelijke contracten, oproepkrachten en uitzendwerkers tot en met werkenden in vaste dienst maar zonder vaste uren (Dekker, 2017). In 2017/2018 had bijna 60 procent van de werkgevers personeel met een tijdelijk contract in dienst. Tien jaar eerder was dat 30 procent van de werkgevers. Vooral in de publieke sector hebben veel organisaties medewerkers met een tijdelijk contract in dienst. Dat was al zo sinds 1997/1998. Bij de overheid, in het onderwijs en de zorg- en welzijnssector schommelt het aandeel werkgevers met tijdelijk personeel tussen ongeveer 60 procent en 70 procent (Putman, 2019).

Flexibele arbeidsrelaties kenmerken zich gemiddeld door minder inkomens- en sociale zekerheid dan niet-flexibele. Daarnaast is veelal sprake van minder ontwikkelings- en opleidingsmogelijkheden. Dit laatste betekent dat bij baanverlies de relatieve kans om opnieuw aan de slag te geraken daalt. Spijtig in het licht van een inclusieve arbeidsmarkt is dat de vertegenwoordiging van groepen met traditioneel een grotere afstand tot de arbeidsmarkt - denk aan laagopgeleiden en mensen met arbeidsbeperkingen - in die flexibele schil de afgelopen jaren juist is gestegen. De afsluiting van de sociale werkvoorziening en invoering van de Participatiewet heeft ervoor gezorgd dat ook mensen die alleen onder aangepaste omstandigheden en met begeleiding kunnen werken, vaker terecht zijn gekomen in de flexibele schil van organisaties - als ze al werkzaam zijn. Een groot deel van hen is buiten het arbeidsproces komen te staan. 
Een andere ontwikkeling die een inclusieve arbeidsmarkt eerder verder weg dan dichterbij lijkt te brengen is de stijging van de AOW-leeftijd. De komende jaren zal een steeds groter deel van de potentiële beroepsbevolking uit ouderen bestaan. Terwijl jongeren de afgelopen jaren profiteerden van de aangetrokken arbeidsmarkt, daalden de baankansen voor ouderen (Vlasblom \& Schippers, 2019). Met het stijgen van de AOW-leeftijd is ook de arbeidsdeelname van ouderen gestegen. Daar staat echter tegenover dat ouderen die hun baan kwijtraken, heel moeilijk opnieuw aan een baan geraken (Vlasblom \& Schippers, 2019). De langdurige werkloosheid onder ouderen is hoog en stijgende. Steeds meer ouderen raken afhankelijk van WW-, bijstands- maar ook arbeidsongeschiktheidsuitkeringen (Gelderblom \& de Koning, 2016). Zeker in regio's waar het aandeel ouderen groot is, zoals in de grensstreken, zet een gebrek aan (deeltijd)werk de bestaanszekerheid onder druk.

Ook voor mensen met een migratieachtergrond is het beeld niet onverdeeld positief. De arbeidsdeelname blijft in algemeenheid achter bij die van autochtonen, en de uitkeringsafhankelijkheid is hoog, hoewel er grote verschillen bestaan tussen de verschillende herkomstgroepen. Voor mensen met een arbeidsbeperking is het beeld eveneens weinig rooskleurig. De arbeidsdeelname van mensen met een arbeidsbeperking bleef de afgelopen jaren, ondanks de inzet op activering in arbeidsongeschiktheidsregelingen en ondanks de invoering van de Participatiewet, achter bij die van mensen zonder beperking.

Er zijn ook ontwikkelingen die meer inclusiviteit lijken te betekenen. Zo hebben vrouwen een inhaalslag gemaakt op de arbeidsmarkt. De afgelopen tien jaar is bijvoorbeeld het aantal werkende vrouwen sterker toegenomen dan het aantal werkende mannen (SCP/CBS, 2018). Toch werkt in Nederland nog steeds driekwart van de vrouwen in deeltijd. Bij de mannen is dat een kwart. Een meerderheid van de vrouwen is niet economisch zelfstandig. Als het gaat om vrouwen aan de top, dan wordt er slechts mondjesmaat vooruitgang geboekt. Het aantal vrouwen in raden van bestuur groeit met ongeveer 1 procentpunt per jaar. En ondanks de invoering van een wettelijk streefcijfer is slechts ongeveer 11 procent van de top (in de 100 grootste bedrijven) vrouw (SCP/CBS, 2016). In de non-profitsector en bij de Rijksoverheid ligt het aandeel topvrouwen met ruim 30 procent echter beduidend hoger.

Bovengenoemde ontwikkelingen en verschillen zijn niet nieuw. Denkend aan inen exclusie op de Nederlandse arbeidsmarkt komen we snel uit bij groepen die gewoonlijk naast dan wel tegenover elkaar geplaatst of geframed worden: hoogversus laagopgeleiden, ouderen versus jongeren, mannen versus vrouwen, mensen met versus mensen zonder migratieachtergrond en mensen met versus mensen zonder arbeidsbeperking. Wel zijn er groepen die in relatief sterke mate geconfronteerd worden met dé kenmerken en uitdagingen van de huidige arbeidsmarkt, zoals flexibilisering, digitalisering en internationalisering, en hun positie steeds onzekerder zien worden. We zien daar een verdieping van scheidslijnen. De volgende paragraaf gaat op enkele daarvan nader in. 


\section{Verklaringen voor achterstanden in de praktijk: twee cases}

In deze paragraaf bespreken we twee cases die beide ingaan op achterstanden op de arbeidsmarkt en die bij ongewijzigd beleid gemakkelijk kunnen verdiepen en verscherpen. De eerste casus laat zien dat er doelgroepen zijn die we 'kwetsbaar' kunnen noemen, wat in onze definitie betekent dat zij minder makkelijk op de omschreven trends op de arbeidsmarkt kunnen inspelen vanwege een gebrekkige gezondheid, opleiding of achterstandspositie. Het betreft de positie van de groep arbeidsbeperkten die bij de evaluatie van de praktijk van de Participatiewet werd belicht (SCP, 2019). Daarnaast belichten we in de tweede casus op welke wijze mensen aan bij- en omscholing doen. Daar zien we onder meer verschillen naar opleidingsniveau en leeftijd. Deze casus belichten we dus minder vanuit een doelgroep en meer vanuit het vraagstuk van duurzame inzetbaarheid als zodanig dat voor scheidslijnen zorgt.

\section{Casus 1: arbeidsbeperkten op de arbeidsmarkt}

De eerste groep die bovenkomt, betreft mensen met arbeidsbeperkingen. Aan het werk geraken en dat werk vasthouden blijkt een grote uitdaging voor deze groep. Arbeidsbeperkten met arbeidsvermogen hebben te maken met verschillende regelingen. Een deel valt onder de verantwoordelijkheid van het Uitvoeringsinstituut Werknemersverzekeringen (UWV) - denk aan mensen in de Wet arbeidsongeschiktheidsvoorziening jonggehandicapten (Wajong) en de Wet Werk en inkomen naar arbeidsvermogen (WIA). En een deel valt onder de verantwoordelijkheid van gemeenten - denk aan mensen in de Participatiewet. Om de mate van arbeidsparticipatie van arbeidsbeperkten in context te plaatsen vergelijkt figuur 1 het aandeel werkende arbeidsbeperkten met arbeidsvermogen - onder verantwoordelijkheid van het UWV - met het aandeel van de totale Nederlandse bevolking en met het aandeel werkenden in andere groepen met een zwakkere positie op de arbeidsmarkt. We zien dat arbeidsbeperkten duidelijk minder vaak aan het werk zijn in vergelijking met de Nederlandse bevolking, maar ook in vergelijking met laagopgeleiden en mensen met een niet-westerse migratieachtergrond. Ook zien we dat de verschillen sinds 2008 eerder groter geworden zijn dan kleiner; de afstand tot de arbeidsmarkt lijkt verdiept.

Dit geldt zowel voor de mensen met een arbeidsongeschiktheidsuitkering (de gedeeltelijk arbeidsongeschikten in de regeling Werkhervatting gedeeltelijk arbeidsgeschikten) als die zonder WIA-uitkering (de zogenaamde 35-minners: mensen die gedeeltelijk arbeidsongeschikt zijn, maar bij wie hun verdienvermogen met hooguit 35 procent is gedaald door de arbeidsongeschiktheid).

Ook voor arbeidsbeperkten onder de Participatiewet stegen de arbeidsmarktkansen de afgelopen jaren niet of nauwelijks. Voor mensen die voorheen recht hadden op een plek in de sociale werkvoorziening daalden de kansen op werk, voor mensen die voorheen instroomden in de Wajong stegen ze, en voor arbeidsbeperkten die voorheen in zouden stromen in de Wet Werk en bijstand was er nauwelijks sprake van een verschil (Van Echtelt e.a., 2019b). Als deze mensen een 


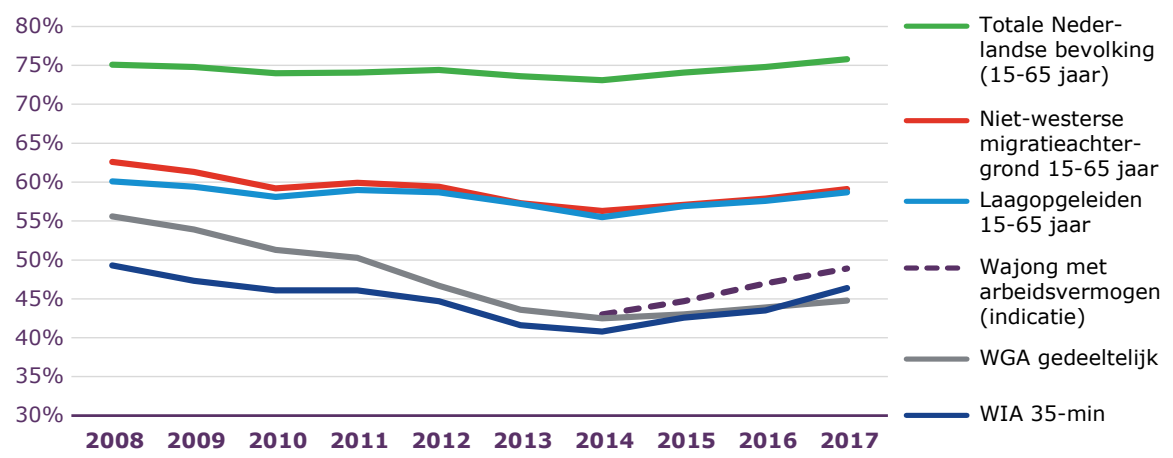

Figuur 1 Ontwikkeling aandeel werkenden binnen groepen mensen met en zonder arbeidsbeperking, eind 2008-2017 (UWV, 2019)

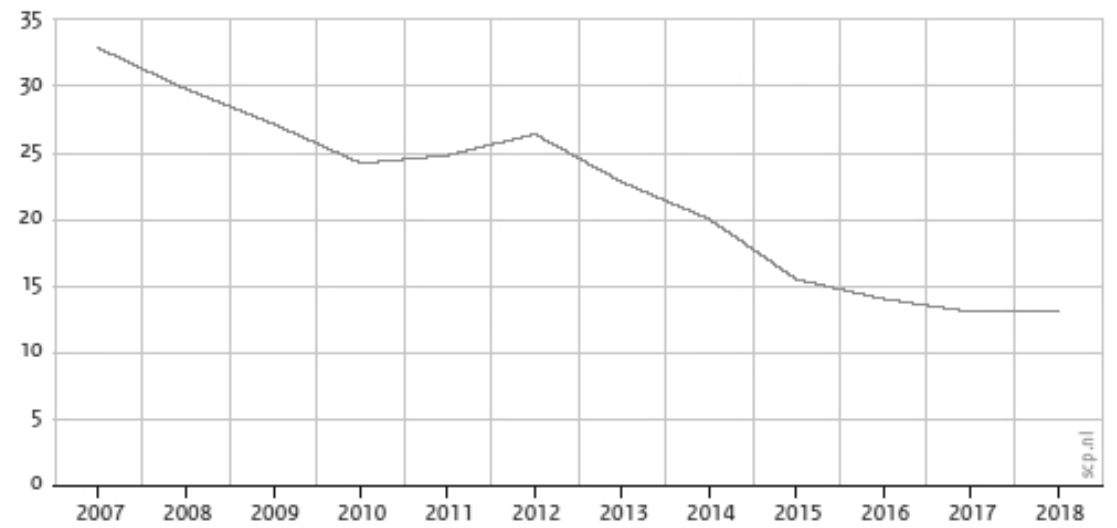

Figuur 2 Aandeel baanvinders binnen de groep jonggehandicapten, met contract voor onbetaalde tijd (Van Echtelt e.a., 2019b)

baan vonden, betrof het in meerderheid een baan in deeltijd en in tijdelijke dienst. De kans op het vinden van een vaste baan daalde. Figuur 2 laat dit zien voor een van de doelgroepen binnen de Participatiewet: de jonggehandicapten. Ook de afgelopen jaren, in tijden van hoogconjunctuur, steeg de kans op het vinden van een vaste baan niet.

De afgelopen decennia stond de arbeidsdeelname van arbeidsbeperkten hoog op de beleidsagenda van opeenvolgende regeringen. Er is veel nieuw beleid geïntroduceerd om deze groep aan het werk te helpen. Beleidswijzigingen hadden onder andere tot doel werkgevers en werknemers meer verantwoordelijkheid te geven voor re-integratie op de arbeidsmarkt. De aandacht in het beleid verschoof: van inkomensbescherming naar activering en re-integratie. De participatiemaatschappij, waarin iedereen naar vermogen deelneemt op de arbeidsmarkt, werd als ideaalbeeld neergezet. Maar ondanks de invoering van een quotum en doelgroepre- 
gister, de introductie van de instrumenten beschut werk en loonkostensubsidie, en meer aandacht voor activering zien we nauwelijks een verdichting van de arbeidsmarktafstand tussen mensen met en zonder arbeidsbeperkingen.

Daarvoor zijn verschillende verklaringen aan te wijzen. Zo bleken de beleidsaannames te rationeel; weinig vanuit gedrag en motivatie van mensen geredeneerd. Dat wil zeggen dat beleidsmakers en politici soms te optimistisch zijn over de arbeidsmogelijkheden van mensen uit deze groep. Daar is veelal ondersteuning van zowel arbeidsbeperkten als werkgevers bij nodig. Het gaat niet vanzelf. Daarbij is ook het belang van het onderhouden van netwerken tussen werkgevers, overheden en instellingen onderschat. Bovendien werkten de financiële prikkels anders dan gedacht. En blijkt de regelgeving erg complex voor betrokkenen, wat het creëren van baankansen voor mensen uit de doelgroep niet ten goede komt.

\section{Casus 2: investeringen in employability}

Een tweede scheidslijn die (sterker) opkomt, betreft die tussen mensen die zich kunnen blijven ontwikkelen, die in aanmerking komen voor bij- of nascholing en hun baankansen zien stijgen of continueren, en die tussen mensen die niet in aanmerking komen voor bij- dan wel nascholing en wier employability eerder afdan toeneemt. De afgelopen decennia is de behoefte aan flexibele organisaties met breed inzetbaar personeel toegenomen. Organisaties zagen zich (steeds meer) gedwongen hun structuur en strategie aan te passen. In een poging de kosten te drukken en aan efficiency te winnen begonnen veel organisaties te reorganiseren, nieuwe markten te zoeken en werk naar lagelonenlanden te verplaatsen (Van Dam Van der Heijden \& Schyns, 2006). Om in deze veranderende wereld het hoofd boven water te houden zijn veel organisaties genoodzaakt hun aanpassingsvermogen en flexibiliteit te vergroten. Ook veranderen de benodigde competenties van werknemers sneller dan eerst. Vooral organisaties in de sectoren onderwijs, overheid en zakelijke dienstverlening vinden dat de benodigde kennis en vaardigheden snel veranderen (Van Echtelt, Putman \& De Voogd-Hamelink, 2019a). Een leven lang leren staat daarom volop in de belangstelling (Maslowski, 2019; Josten e.a., 2019). Samen met de behoefte aan meer flexibiliteit bij werkgevers zijn werknemers (meer) zelf verantwoordelijk geworden voor de eigen loopbaanontwikkeling en werkzekerheid.

Onderzoek van Van Vuuren, Caniëls en Semeijn (2011) laat zien dat die employability afhankelijk is van de mate waarin mensen in staat zijn c.q. worden gesteld om een leven lang te leren. Hoe meer men een leven lang leert, hoe groter de duurzame inzetbaarheid; dat wil zeggen hoe groter het werkvermogen, de employability en de vitaliteit, zelfs voor oudere werknemers. Daaruit kan opgemaakt worden dat een leven lang leren waardevol is voor duurzame inzetbaarheid over de volle breedte (employability, werkvermogen en vitaliteit) en voor elke leeftijd.

Wat we zien is dat juist de meest kwetsbare groepen op de arbeidsmarkt, mensen die ook vaak in tijdelijke dienst zijn, minder vaak in aanmerking komen voor een leven lang leren. Werkgevers investeren bijvoorbeeld veel minder in de scholing van tijdelijke werknemers dan in medewerkers in vaste dienst. 


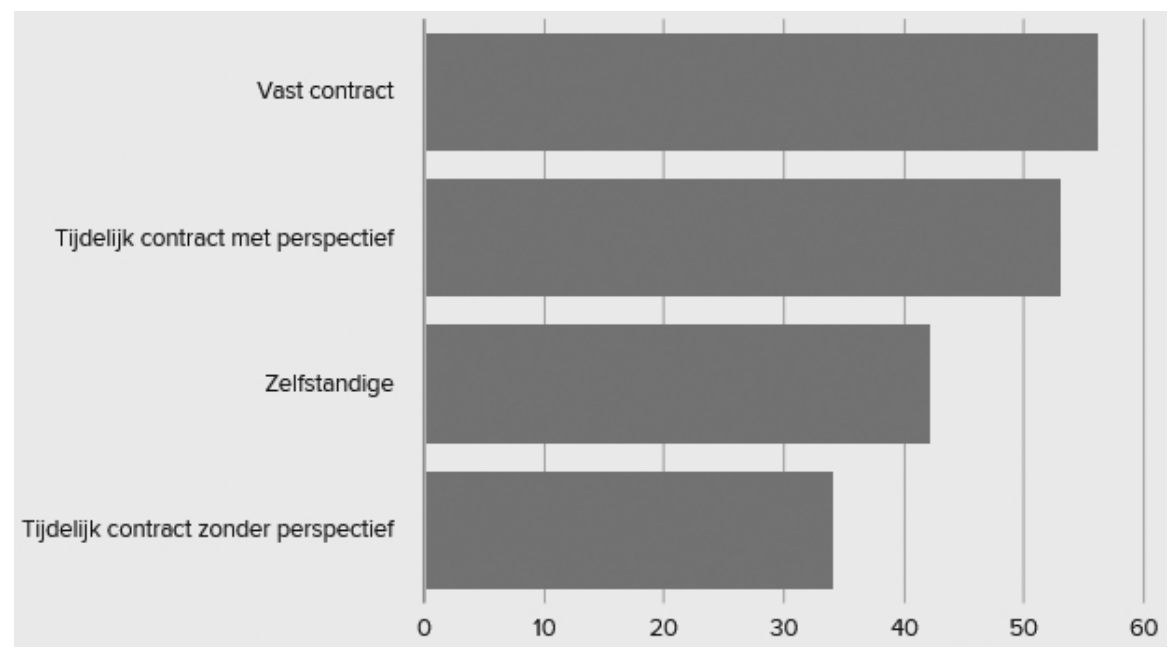

Figuur 3 Deelname aan werkgerelateerde cursussen in 2016-2018 (in procenten) (De Grip e.a., 2018)

Het Researchcentrum voor Onderwijs en Arbeidsmarkt (ROA) (De Grip e.a., 2018) liet zien dat slechts een derde van de werknemers met een tijdelijk dienstverband (zonder uitzicht op een vaste aanstelling) de twee jaren daarvoor een cursus volgden, tegenover ruim de helft van de werknemers met een vast contract (zie figuur 3). Het beeld dat naar voren komt uit de arbeidsaanbodpanels van het Sociaal en Cultureel Planbureau (SCP) is gelijksoortig (Josten e.a., 2019). Organisaties vrezen dat hun investering verdampt als een tijdelijke medewerker vertrekt. Tijdelijke werknemers spelen daar op in en zijn bereid zelf geld bij te leggen en scholing in hun eigen tijd te volgen, zo liet het ROA zien. Van de ondervraagde tijdelijke werknemers volgde 60 procent cursussen (deels) in hun vrije tijd. Van de mensen met een vast contract deed ruim de helft de opleiding onder werktijd.

Ook bij andere groepen zien we verschillen. Laagopgeleide werkenden scholen zich minder vaak dan hogeropgeleiden (Portegijs, 2019). Zo hadden hoogopgeleide werkenden in 2015/2016 twee keer zo vaak een opleiding of cursus gevolgd als laagopgeleide werkenden. De middelbaar opgeleiden zaten daar tussenin. Ook de aanstellingsduur maakt uit. Werkenden met een kleinere deeltijdaanstelling scholen zich minder dan werkenden die vier of vijf dagen per week werken (Portegijs, 2019). Oorzaken voor deze verschillen worden veelal gezocht in de kostenbateninschatting die werkgever en werknemer maken.

Doorzetting van deze ontwikkeling betekent op den duur een grotere afstand tussen mensen die wel en niet (kunnen) investeren in hun employability. Achterblijvende investeringen in scholing zorgen ervoor dat de inzetbaarheid, productiviteit en daarmee arbeidsmarktkansen van deze groepen eerder divergeren dan dat zij convergeren. Opvallend is dat de eerdergenoemde groep - arbeidsbeperk- 
ten - alle kenmerken heeft van de groep die relatief weinig in aanmerking komt voor investeringen in leven lang leren. Het gaat in meerderheid om mensen met een lage opleiding, een tijdelijk contract en deeltijdaanstelling.

Verklaringen voor het verschil tussen wat beoogd wordt met beleid gericht op employability en wat we zien in de praktijk zijn meerledig. Allereerst zien we dat de mogelijkheden om employability te onderhouden dan wel te vergroten sterk afhankelijk zijn van meer structurele aspecten van de arbeidsmarkt, zoals de mate van werkzekerheid en de continuïteit in werkgevers- en werknemersrelaties. Daarnaast houdt beleid weinig rekening met de individuele afwegingen die werkgevers maken in termen van investeringen; voor werkgevers loont het eerder te investeren in werknemers die de investering met zekerheid om weten te zetten naar een hogere productiviteit dan in werknemers voor wie die veel onzekerder is.

\section{Naar nieuwe scheidslijnen?}

Verwacht wordt dat de dynamiek waarmee de arbeidsmarkt de komende jaren omgeven is, zal vragen om en leiden tot een ander type werknemer: de ondernemer van zijn of haar eigen kansen gedurende zijn of haar gehele arbeidzame leven. Niet iedereen heeft de capaciteiten en vaardigheden om dat te zijn. Om te spreken over een nieuwe scheidslijn tussen mensen voor wie dat weggelegd is en mensen voor wie dat niet het geval is, is het belangrijk naar de mobiliteit te kijken. Een voorwaarde voor een scheidslijn is namelijk dat er weinig mobiliteit plaatsvindt: slechts weinigen overschrijden de grens en verplaatsen zich van de ene groep naar de andere (De Beer, 2016).

Wat we de afgelopen jaren gezien hebben, is dat investeringen in scholing bij dezelfde groepen lijken neer te slaan. De route naar blijvende investeringen in naen bijscholing loopt vooral via de overgang van tijdelijk naar vast werk. Voor zover deze overgang mogelijk is, kan geen sprake zijn van een scheidslijn. Voor sommigen is deze overgang weggelegd. Daarentegen niet voor de meest kwetsbaren, zo laten de afgelopen decennia zien. Daar zien we een verdieping van de scheidslijn. Daar komt bij dat de overgang van 'arbeidsbeperkt' naar 'niet arbeidsbeperkt' voor een behoorlijk deel van deze groep niet mogelijk is.

Om scheidslijnen niet scherper te laten worden kan het van belang zijn om inzicht te hebben in de verklaringen voor het achterblijven van zowel sommige doelgroepen op de arbeidsmarkt als van het urgentiebesef rond duurzame inzetbaarheid. Uit de voorbeelden die in deze bijdrage zijn uitgewerkt, blijkt dat in elk geval rekening gehouden moet worden met de volgende factoren:

- Beleidsaannames die afstand creëren van de werkelijkheid op de arbeidsmarkt. Bijvoorbeeld omdat ze te rationalistisch zijn geformuleerd, terwijl gedragskeuzes van zowel werknemers als werkgevers in hoge mate gestuurd worden door andere zaken dan wetgeving, zoals het elkaar kennen, de invloed en steun van sociale netwerken, de afstand tussen wonen en werken, de organisatie van ondersteuning en begeleiding en het vertrouwen in de toekomst. 
- Ook de inzet en motivatie van werkgevers en de directe omgeving van mensen is een belangrijke factor in het inzetten op bij- en omscholing of het inrichten van een aangepaste werkomgeving.

- De vraag of bij- en omscholing tijdens werkuren mag plaatsvinden, is mogelijk een belangrijke factor die scheidslijnen kan versterken tussen diegenen die dat wel kunnen en mogen en die werknemers voor wie dat niet geldt.

- De wijze waarop mensen met de combinatiedruk omgaan.

- De aanwezigheid van een achtervang als de werkplek niet gerealiseerd wordt met aanpassingen, of als het bij- en omscholen niet van de grond komt. Is er dan - bijvoorbeeld van overheidswege - een ondersteuning (werknemers) of ontzorging (werkgevers)?

- De rol van stigma van bepaalde groepen op de arbeidsmarkt kan een belangrijke factor van belang zijn voor de vraag of groepen hun achterstanden weten en durven weg te werken (denk aan mensen met psychische beperkingen).

Het betreft dus factoren die te maken hebben met de inrichting van onze systemen van arbeidsmarkt en onderwijs en de uitwerking van wetgeving zoals de Participatiewet. Het betreft ook verklaringen die te maken hebben met motivaties en gedragingen van zowel werknemers als werkgevers, die ook deels onder invloed van de beschreven systemen staan. De aanpak van scheidslijnen in onderwijs en werk vraagt om een samenhangende aanpak op al deze aspecten.

\section{Tot slot: pleidooi voor uitvoerbaarheid door kennis van en voor het arbeidsmarktbeleid}

Een eerste conclusie uit onze bijdrage is dat een gedegen analyse van reeds bestaande scheidslijnen op de arbeidsmarkt cruciaal is voor effectief beleid, maar dat kennis over het verdiepen van oude en het creëren van nieuwe scheidslijnen minstens zo relevant is.

Een tweede conclusie is dat de geschetste aannames in beleid rond zelfredzaamheid van bijvoorbeeld arbeidsbeperkten of de mogelijkheden van werkgevers om beschut werk te realiseren en in te zetten op bij- en omscholing bijvoorbeeld buiten werktijden niet altijd realistisch zijn. Er zal veel beter moeten worden aangesloten bij de werkelijke mogelijkheden van mensen en organisaties om dat voor elkaar te krijgen. Financieel, maar ook organisatorisch en persoonlijk.

De motivaties en gedragingen van zowel werknemers als werkgevers en onderwijsinstanties blijken zeer relevante verklarende factoren in de praktijk, waar vaak te weinig rekening mee gehouden wordt. Zowel de ervaringen met de Participatiewet als met de praktijk van een leven lang leren laten ons dat zien. Dat is relevante kennis voor beleid.

Als aannames onder beleid niet te ver af mogen staan van de praktijk, is de waarschuwing op zijn plaats om nieuwe systeemwijzigingen niet 'van achter het bureau' te doordenken en formuleren. Er is meer wisselwerking nodig de komende jaren tussen onderzoek, beleid en de praktijk van de arbeidsmarkt, ook 
als het gaat om het uitwerken van de voorstellen van de WRR en de commissieBorstlap naar de praktijk.

Voorafgaand aan nieuw beleid zou er dus beter getoetst kunnen worden - via vormen van ex ante evaluatie - hoe maatregelen mogelijk zullen uitpakken voor kwetsbare groepen zoals arbeidsbeperkten en wat het betekent voor het urgentiebesef rond duurzame inzetbaarheid. Dat levert veel meer kennis van beleid op die onmisbaar is voor de uitvoerbaarheid ervan.

\section{Literatuur}

Beer, P. de (2016). De eenvoud van de tweedeling. Sociologie Magazine, 24 (1): 6-8.

CBS/TNO (2019). Dynamiek op de Nederlandse arbeidsmarkt. Den Haag: Centraal Bureau voor de Statistiek/TNO.

Commissie Regulering van Werk (2020). In wat voor land willen wij werken? Naar een nieuw ontwerp voor de regulering van werk. Den Haag: Commissie Regulering van Werk.

Dam, K. van, Heijden, B. van der, \& Schyns, B. (2006). Employability en individuele ontwikkeling op het werk. Gedrag \& Organisatie, 19 (1): 53-68.

Dekker, F. (2017). Flexibilisering in Nederland: trends, kansen en risico's. In: WRR, Voor de zekerheid. De toekomst van flexibel werkenden en de moderne organisatie van arbeid. Den Haag: Wetenschappelijke Raad voor het Regeringsbeleid.

Echtelt, P. van, Putman, L., \& Voogd-Hamelink, M. de (2019a). Arbeidsmarkt in kaart: werkgevers editie 2. Den Haag: Sociaal en Cultureel Planbureau.

Echtelt, P. van, Sadiraj, K., Hoff, S., Muns, S., Karpinska, K., Das, D., \& Versantvoort, M. (2019b). Eindevaluatie van de Participatiewet. Den Haag: Sociaal en Cultureel Planbureau.

Gelderblom, A., \& Koning, J. de (2016). De arbeidsmarktpositie van ouderen. Rotterdam: SEOR.

Grip, A. de, Belfi, B., Fouarge, D., Künn-Nelen, A., Peeters, T., \& Poulissen, D. (2018). Levenslang leren en competentie-ontwikkeling (beleidsrapport). Maastricht: ROA.

Josten, E., Portegijs, W., Merens, A., \& Voogd-Hamelink, M. de (2019). Arbeidsmarkt in kaart: wel- en niet-werkenden editie 1. Den Haag: Sociaal en Cultureel Planbureau.

Maslowski, R. (2019). Grenzen aan een leven lang leren. Den Haag: Sociaal en Cultureel Planbureau.

Portegijs, W. (2019). Neemt een leven lang leren onder werkenden toe? In: E. Josten, W. Portegijs, A. Merens \& M. de Voogd-Hamelink (red.), Arbeidsmarkt in kaart: wel-en niet-werkenden editie 1. Den Haag: Sociaal en Cultureel Planbureau, kaart 4.

Putman, L. (2019). Welke organisaties maken gebruik van flexibele arbeid en waarom? In: P. van Echtelt, L. Putman \& M. de Voogd-Hamelink (red.), Arbeidsmarkt in kaart: werkgevers editie 2. Den Haag: Sociaal en Cultureel Planbureau.

SCP/CBS (2016). Emancipatiemonitor 2016. Den Haag: Sociaal en Cultureel Planbureau/ Centraal Bureau voor de Statistiek.

SCP/CBS (2018). Emancipatiemonitor 2018. Den Haag: Sociaal en Cultureel Planbureau/ Centraal Bureau voor de Statistiek.

SCP (2019). Eindevaluatie van de Participatiewet. Den Haag Sociaal en Cultureel Planbureau.

SER (2019). Hoge verwachtingen: Kansen en belemmeringen voor jongeren in 2019. Den Haag: Sociaal Economische Raad. 
UWV (2019). UWV Monitor Arbeidsparticipatie 2018. Aan het werk zijn, komen en blijven van mensen met een arbeidsbeperking. Amsterdam: UWV.

Vlasblom, J.D., \& Schippers, J. (2019). Werkloze ouderen weer aan het werk? Het effect van reserveringsloon en zoekintensiteit. Tijdschrift voor arbeidsmarktmarktvraagstukken, 35 (1).

Vuuren, T. van, Caniëls, M., \& Semeijn, J.H. (2011).Duurzame inzetbaarheid en een leven lang leren. Gedrag \& Organisatie, 24 (4): 356-373.

WRR (2020). Het betere werk. De nieuwe maatschappelijke opdracht. Den Haag: Wetenschappelijke Raad voor het Regeringsbeleid. 